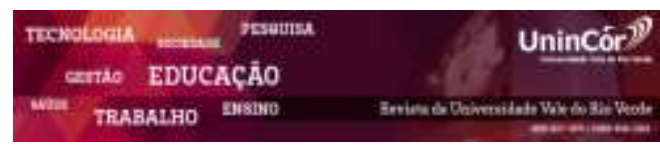

Revista da Universidade Vale do Rio Verde ISSN: 1517-0276 / EISSN: 2236-5362 Vol. $16 \mid$ n. $1 \mid$ Ano 2018

Márcia Aparecida Andreazzi Centro Universitário de Maringá/ ICETI. marcia.andreazzi@unicesumar.edu.br

Jéssica Silva Pinto

Centro Universitário de Maringá jessicasilva_02@hotmail.com

José Maurício Gonçalves dos Santos Centro Universitário de Maringá jose.santos@unicesumar.edu.br

Fábio Luiz Bim Cavalieri Centro Universitário de Maringá/ ICETI fabio.cavalieri@unicesumar.edu.br

Natália Christina da Silva Matos Centro Universitário de Maringá natalia.matos@unicesumar.edu.br

Isadora Olivato Barbieri Centro Universitário de maringaisadora_olivato@hotmail.com

\section{DESEMPENHO DE FRANGOS DE CORTE CRIADOS EM AVIÁRIO CONVENCIONAL E DARK-HOUSE}

\begin{abstract}
RESUMO
A avicultura brasileira é uma das mais desenvolvidas do mundo, contudo, com o expressivo crescimento e o progresso científico, são necessários estudos sobre técnicas de alojamento e ambiência para criação das aves. Um aviário deverá garantir um ambiente confortável para as aves, garantindo os altos índices de produtividade. Neste contexto, buscando transpor os desafios da ambiência, tem se adotado a construção dos aviários Dark-House com cortinas e do tipo "solid wall", que propiciam um maior controle do ambiente de criação e maior desempenho das aves. $\mathrm{O}$ objetivo desse trabalho foi estudar e comparar o desempenho de frangos de corte criados em aviários convencionais, Dark-House com cortina e Dark-House com parede de alvenaria - "solid wall". Foram acompanhadas seis criadas de frangos de corte em 15 aviários comerciais, sendo 5 convencionais, 5 Dark-House com cortinas e 5 Dark-House "solid wall". A linhagem e o manejo alimentar não diferiram entre as criadas. Foram coletados os dados de ganho de peso diário, peso ao abate, idade ao abate, conversão alimentar e taxa de mortalidade. Os dados evidenciaram que a criação de frango de corte em aviários que empregam o sistema Dark-House "solid wall", resultou em índices zootécnicos superiores $(\mathrm{P}<0,05)$ aos aviários convencionais, porém, não diferiu dos aviários DarkHouse com cortina. Estes dados reforçam que estudos que avaliam o desempenho das aves em diferentes tipos de aviários são fundamentais para fortalecer a cadeia produtiva avícola.
\end{abstract}

Palavras-chave:Ambiência. Avicultura. Dark-house. Instalações avícolas. Solild wall.

\section{PERFORMANCE OF BROILERCHICKENSCREATED IN CONVENTIONAL AVIARY AND DARK- HOUSE}


showed that the creation of broilers chickens in poultry farms employing the solid wall Dark-House resulted in superior performance indexes $(\mathrm{P}<0.05)$ to conventional aviaries, however, did not differ from aviaries Dark-House with curtain. These data reinforce that studies evaluating the performance of the broiler chickens in aviaries different types are essential to strengthen the poultry production chain.

Keywords: Ambience. Aviaries. Dark-Horse. Poultry. Solid wall

Recebido em: 10/10/2017 - Aprovado em: 05/04/2018 - Disponibilizado em: 15/07/2018

\section{INTRODUÇÃO}

A avicultura brasileira se destaca mundialmente, colocando o Brasil como terceiro maior produtor e maior exportador mundial de carne de frango, sendo que a região sul se destaca neste cenário, sendo responsável por $62,34 \%$ da produção nacional (ABPA, 2016).

Estes bons índices alcançados se sustentam em genética, nutrição, ambiência e mão de obra qualificada. Devido a grande evolução nesta cadeia produtiva, a granjas se constituem em grandes núcleos de produção de proteína animal (VIGODERIS, 2007).

Tinoco (2001) afirmou que, mesmo com o expressivo crescimento nas exportações e no progresso científico verificado na avicultura, são necessários constantemente estudos sobre formas de alojamento que busquem a melhor ambiência para criação das aves. Para Nascimento (2010) é necessário entender os aspectos termodinâmicos que envolvem os animais, pois devido às mudanças climáticas, tornam-se essenciais mais estudos relacionados às construções rurais e ao bem-estar animal. De fato, Rodrigues et al (2009) relataram que qualquer problema estrutural das instalações que resulte em situações inadequadas de ventilação, renovação de ar, acúmulo de gases e varia- ções térmicas pode ser considerado fator de risco para a criação de frangos de corte. Segundo Damasceno et al. (2010), um aviário deverá amenizar as sensações de desconforto térmico para as aves, impostas por climas extremos, e garantir ambientes confortáveis, para que se alcance altos índices de produtividade.

Desta forma, o ideal é que os produtores adotem tecnologias desenvolvidas que resultem em aviários climatizados, criando um ambiente confortável na produção. Neste contexto, buscando transpor os desafios da ambiência, Gallo (2009) cita a tecnologia dos sistemas "DarkHouse". Os aviários Dark-House se constituem em tecnologia recente no Brasil e, de acordo com Gallo (2009) este sistema, que propicia a condução de lotes em ambiente e luminosidade controlada, mantém as aves mais calmas, permite uma maior densidade de aves, reduz a incidência de dermatoses, a mortalidade e o consumo de ração e melhora a conversão alimentar, o ganho de peso diário, resultando em melhores resultados zootécnicos e econômicos para as empresas e produtores.

Contudo, como novas tecnologias sempre estão emergindo, atualmente várias empresas integradoras tem avançado no segmento das construções dos aviários e tem adotado aviários 
Dark-House construídos com paredes de alvenaria ("solid wall"). Alguns dados têm mostrado que estes aviários apresentam índices superiores de produtividade do lote quando comparados aos aviários convencionais e, inclusive, aos DarkHouse construídos com isolamento lateral por cortinas.

Desta forma, o objetivo desse trabalho foi estudar e comparar o desempenho de frangos de corte criados em aviários convencionais, DarkHouse com cortina e Dark-House construídos com paredes de alvenaria - "solid wall".

\section{METODOLOGIA}

O presente trabalho foi conduzido durante o ano de 2014, em quinze aviários comerciais, localizados na região noroeste do Paraná/ Brasil, caracterizada por clima subtropical temperado, latitude $23^{\circ} 25^{\prime} \mathrm{S}$, longitude $51^{\circ} 57^{\prime} \mathrm{W}$ e altitude $596 \mathrm{~m}$.

Foram acompanhadas seis criadas de frangos de corte (aproximadamente um ano), por aviário, e o total de aves foi, em média, 30.000 aves alojadas/ aviário. Destes 15 aviários, 5 eram aviários convencionais (C), 5 Dark-House (DH) com cortinas e 5 Dark-House construídos com parede de alvenaria, tipo "solid wall" (SW).

Os aviários do tipo Convencional contavam com sistema de ventilação artificial do tipo túnel de pressão positiva, aspersores, com isolamento lateral por cortinas amarelas e densidade de 11,60 aves $\mathrm{m}^{2}$. Os aviários do tipo DH apresentavam sistema de ventilação artificial do tipo túnel de pressão negativa, painel evaporativo (celulose), com isolamento lateral por cortinas pretas na face interna e prata na face externa, para o controle da luminosidade e densidade de $13,72 \mathrm{~m}^{2}$. Os aviários do tipo $\mathrm{SW}$ apresentavam sistema de ventilação artificial do tipo túnel de pressão negativa, painel evaporativo (celulose), com isolamento lateral por paredes de alvenaria para controle da luminosidade e densidade de 13,80 aves $\mathrm{m}^{2}$.

A linhagem e o manejo alimentar não diferiram entre as criadas. Todos os aviários estavam equipados com comedouros automáticos e bebedouros automáticos tipo nipple. A cama usada nos aviários foi à base de maravalha e casca de café, sendo revolvida sempre que necessário.

Para se avaliar os índices zootécnicos, foram coletados, em todas as criadas, os dados de ganho de peso diário, peso ao abate, idade ao abate, conversão alimentar e taxa de mortalidade.

Ao final, os resultados obtidos foram submetidos à análise de variância e ao teste de Tukey $5 \%$.

\section{RESULTADOS E DISCUSSÃO}

Os dados médios de ganho de peso diário, peso ao abate, idade ao abate, conversão alimentar e taxa de mortalidade em aviários convencionais, Dark-House com cortina e Dark-House “solid wall” estão mostrados na tabela 1.

Os resultados evidenciaram que a criação de frangos de corte em aviários que empregam o sistema Dark-House "solid wall", resultou em índices zootécnicos superiores $(\mathrm{P}<0,05)$ aos aviários convencionais, porém, não diferiu dos aviários "Dark-House" com cortina. 
Tabela 1- Valores médios de ganho de peso diário, idade ao abate, peso médio ao abate e taxa de mortalidade de frangos de corte criados em aviários convencionais, Dark-House com cortinas e "solid wall".

\begin{tabular}{cccc}
\hline Parâmetros avaliados & \multicolumn{3}{c}{ Tipo de aviário } \\
\cline { 2 - 4 } & Convencional & Dark-House com cortina & Dark-House com parede \\
\hline Ganho de peso diário $(\mathrm{g})$ & $58,60 \mathrm{~b}$ & $59,99 \mathrm{ab}$ & $62,01 \mathrm{a}$ \\
Idade ao abate $($ dias $)$ & $48,30 \mathrm{~b}$ & $47,20 \mathrm{ab}$ & $46,86 \mathrm{a}$ \\
Peso médio ao abate $(\mathrm{g})$ & $2.720,00 \mathrm{~b}$ & $2.806,00 \mathrm{~b}$ & $2.882,00 \mathrm{a}$ \\
Conversão alimentar & $1,950 \mathrm{~b}$ & $1,920 \mathrm{~b}$ & $1,791 \mathrm{a}$ \\
Taxa de mortalidade $(\%)$ & $5,86 \mathrm{~b}$ & $4,63 \mathrm{~b}$ & $4,40 \mathrm{a}$ \\
\hline
\end{tabular}

* Letras diferentes na mesma linha, diferem entre si $(\mathrm{P}<0,05)$.

Verdi (2009) também comparou o desempenho de frangos de corte criados em aviário convencional e Dark-House com cortinas e evidenciou valores superiores para o sistema DarkHouse, contudo, os valores citados pelo autor para ganho de peso diário, 53,10 e 57,80 (g) e peso vivo médio ao abate, 2,466 e 2,618 (kg), para frangos criados em sistema convencional e Dark-House, respectivamente, foram menores aos encontrados nesta pesquisa. Por outro lado, os valores para conversão alimentar, 1,932 (C) e 1,844 (DH), foram semelhantes. A taxa de mortalidade citada por Verdi (2009) foi de 4,57\% (C) e $4,75 \%$ (DH), que evidencia o alto índice de mortalidade observado neste trabalho nos aviários convencionais $(5,86 \%)$.

A tecnologia dos aviários com ambiente controlado mostra-se viável técnica e economicamente e traz como benefícios, além da otimização de mão de obra, maior bem estar para as aves, que resulta em maior ganho de peso, melhor conversão alimentar e qualidade de carcaça e menor mortalidade. Todos estes pontos positivos somados geram estabilidade e maior lucratividade produtor/empresa, economia de água, ração, energia elétrica e combustível e maior produção por área. De fato, Gallo (2009) afirmou que o sistema Dark-House traz uma série de benefícios nos índices de desempenho, reduzindo os custos de produção e aumentando o ganho final para os produtores. $\mathrm{O}$ autor afirmou que por ter um maior controle térmico, a densidade pode ser maior e ainda apresenta índices zootécnicos melhores que o aviário convencional. Sabe-se que as aves atingem sua produtividade ótima se forem mantidas em ambiente termoneutro, pois assim, a energia do alimento não é desviada para compensar desvios térmicos em relação ao intervalo de termoneutralidade para eliminar ou manter seu calor (MOSTAFA et al., 2012; CORKERY et al., 2013; CURI et al., 2014).

$\mathrm{Na}$ produção de frangos de corte tanto o ambiente térmico, representado por temperatura, umidade relativa, velocidade do ar e radiação, como o aéreo, representado pela presença de poeira e gases, como $\mathrm{NH}_{3}$ e $\mathrm{CO}_{2}$, exercem efeitos sobre a resposta produtiva e bem estar animal, principalmente quando as aves estão na fase final de produção (CURI et al., 2014).

Os aviários que empregam o sistema convencional apresentaram valores inferiores nos índices analisados. Este fato pode ser explicado pela falta de um maior controle no ambiente interno do barracão, sobretudo com relação à umidade e temperatura. Damasceno et al. (2010) afirmaram que um aviário deve amenizar as sensações de desconforto térmico para as aves, para que se alcance altos índices de produtividade. 
Caso a instalação seja deficitária quanto à sua função de proporcionar conforto térmico ao ambiente, os resultados da criação serão negativos (RODRIGUES et al, 2009).

Apesar dos resultados de desempenho superiores evidenciados neste trabalho com os aviários Dark-House e, principalmente, o DarkHouse "solid wall", cabe destacar as afirmações de Souza e Molento (2015) que reportaram, em discussão sobre atualidades e perspectivas em bem-estar animal, um estudo comparativo entre granjas de frango de corte do Rio Grande do Sul e da Bélgica, demonstrando que as granjas do Brasil apresentaram maiores escores nos princípios de boa alimentação, bom alojamento e boa saúde e, as autoras sugeriram que estes dados favoráveis ao Brasil podem ser reflexos do sistema de produção adotados pelas granjas convencionais, caracterizado pelo uso de iluminação natural e pela menor densidade de alojamento, em comparação aos aviários escuros. Desta forma, como o Brasil está em um momento onde os avicultores estão migrando suas criações dos barracões convencionais para os escuros (DarkHouse), tal fato poderá prejudicar as exportações, caso a iluminação natural seja futuramente um requisito obrigatório para o Bem-Estar Animal, concluíram as autoras.

\section{CONCLUSÃO}

De acordo com os dados levantados, concluiu-se que o sistema de criação de frango de corte em aviários do tipo Dark-House, sobretudo do tipo "solid wall", apresentou os melhores índices zootécnicos.

Para fortalecer a cadeia produtiva avícola, estudos sobre desenvolvimento tecnológico dos aviários é fundamental, visto que, refletem diretamente sobre o desempenho das aves.

\section{BIBLIOGRAFIA}

ABPA - Associação Brasileira de Proteína Animal. Relatório Anual 2016. Disponível em <http://abpabr.com.br/storage/files/versao_final_para_envio_digit al_1925a_final_abpa_relatorio_anual_2016_portugues _web1.pdf> acessado em 10/05/2016.

CORKERY, G.; WARD, S.; KENNY, C.;

HEMMINGWAY, P. Monitoring Environmental

Parameters in Poultry Production Facilities. Computer Aided Process Engineering (CAPE) Forum 2013, Anais...Graz University of Technology, Austria, 12p.

DAMASCENO, F. A.; SCHIASSI, L.; SARAZ, J.A.O. et al. Concepções arquitetônicas das instalações utilizadas para a produção avícola visando o conforto térmico em climas tropicais e subtropicais. Pubvet, v.4, n. 42, 2010.

CURI, T. M. R. C.; VERCELLINO, R., MASSARI, J. M. et al. Geoestatística para a avaliação do controle ambiental do sistema de ventilação em instalações comerciais para frangos de corte. Engenharia Agrícola, v.34, n.6, p.1062-1074, 2014.

GALLO, B.B. Dark-House: manejo x desempenho frente ao sistema tradicional. In: $10^{\circ}$ Simpósio Brasil Sul de Avicultura, 2009, Chapecó, SC. Anais...Embrapa Suínos e Aves, 140p.

MOSTAFA, E., IN-BOK LEE, SANG-HYEON, SONG et al. Computational fluid dynamics simulation of air temperature distribution inside broiler building fitted with duct ventilation system. Biosystems Engineering. v.112, p.293-303, 2012.

RODRIGUES, V.C.; SILVA, I.J.O.; NASCIMENTO, S.T. et al. Instalações avícolas no estado de São Paulo - Brasil: os principais pontos críticos quanto ao bem estar e conforto térmico animal. Thesis, n.11, p. 24$30,2009$.

VERDI, P. Inovação mudando o mundo rural - Sistemas de automação em Dark-House para ambiência de frango de corte. Workshop Embrapa Suínos e Aves. 2009. Disponível em.

<http://www.cnpsa.embrapa.br/down.php?tipo=event os\&cod_arquivo=119> acessado em 11/05/2016.

VIGODERIS, R. B., TINÔCO, I. F. F., LACERDA FILHO, A. F.et al. Construção de túnel de vento reduzido, visando a avaliação de argila expandida em sistemas de resfriamento adiabático evaporativo para arrefecimento térmico em galpões de produção animal. Engenharia Agrícola, v. 15, p. 191-199, 2007. 
SOUZA, A. P.O; MOLENTO, C. F.M. Cuidados além da certificação- atualidades e perspectivas em bemestar animal. Revista Avicultura Paraná. v. 45, p. 334-37. 2015.

TINÔCO, I. F.F. Avicultura industrial: Novos conceitos de materiais, concepções e técnicas construtivas disponíveis para galpões avícolas brasileiros. Revista Brasileira de Ciência Avícola, v.3, n.1, p.1-26, 2001.

\section{Márcia Aparecida Andreazzi.}

Zootecnista, professora Doutora do Programa de PósGraduação em Tecnologias Limpas e do Curso de Medicina Veterinária / UNICESUMAR.

\section{Jéssica Silva Pinto}

Médica Veterinária. Curso de Medicina Veterinária. Centro Universitário de Maringá/ UNICESUMAR.

José Maurício Gonçalves dos Santos

Médico Veterinário, professor doutor do Curso de Medicina Veterinária/ UNICESUMAR.

Fábio Luiz Bim Cavalieri
Zootecnista e Médico Veterinário, professor Doutor
do Programa de Pós-Graduação em Tecnologias
Limpas e do curso de Medicina Veterinária/
UNICESUMAR

Natália Christina da Silva Matos
Gestora em Agronegócio. Mestranda do Programa de
Pós-Graduação em Tecnologias Limpas /
UNICESUMAR/

Isadora Olivato Barbieri

Médica Veterinária. Curso de Medicina Veterinária.

Centro Universitário de Maringá/ UNICESUMAR 